\title{
EFFICACY OF ORAL GLUTATHIONE ADDITION IN LUTEIN SUPPLEMENTATION ON CONTRAST SENSITIVITY IMPROVEMENT IN DRY AGE-RELATED MACULAR DEGENERATION: A RANDOMIZED CONTROLLED TRIAL
}

\author{
RAMZI AMIN*, EDWIN BAYU SAPUTRA
}

Department of Ophthalmology, Sriwijaya University, Palembang, Indonesia. Email: dr.rachmat.hidayat@gmail.com Received: 14 November 2018, Revised and Accepted: 19 December 2018

\begin{abstract}
Objective: Age-related macular degeneration (ARMD) is the macular abnormality causing central vision loss in the elderly. One prevention for ARMD is the provision of antioxidants, such as lutein. Reduced form of glutathione (GSH) is a source of cysteine and sulfhydryl, playing a role in detoxification, transport, and metabolic processes. Both are prospected to have a synergistic effect in the prevention of ARMD. This study aimed to determine the efficacy of GSH addition in lutein supplementation to improve the contrast sensitivity of dry type ARMD patients.
\end{abstract}

Methods: This randomized controlled trial was conducted at an eye hospital and a tertiary general hospital from April 2016 to June 2016 . This study involved 22 dry ARMD patients. Subjects were randomized and divided into treatment groups with 20 mg lutein with the addition of 500 mg GSH and 20 mg lutein only, for 30 days. Contrast sensitivity measurement was performed with Lea Numbers ${ }^{\circledR}$ Low Contrast Flip Chart before and after the treatment. Contrast sensitivity was analyzed comparatively with paired t-test.

Results: Contrast sensitivity improvement was observed in both the groups. Contrast sensitivity improvement of the group with additional GSH $(3.62 \pm 1.44, \mathrm{p}<0.05)$ was a 3 -fold of the lutein group only $(1.25 \pm 0.44, \mathrm{p}>0.05)$. The result was statistically significant for the group treated with GSH addition.

Conclusion: GSH addition in lutein supplementation provoked better contrast sensitivity improvement in dry ARMD patients.

Keywords: Age-related macular degeneration, Glutathione, Lutein, Antioxidants, Contrast sensitivity.

(C) 2019 The Authors. Published by Innovare Academic Sciences Pvt Ltd. This is an open access article under the CC BY license (http://creativecommons. org/licenses/by/4. 0/) DOI: http://dx.doi.org/10.22159/ajpcr.2019.v12i3.30753

\section{INTRODUCTION}

Age-related macular degeneration (ARMD) is a macular disorder characterized by one or more of several symptoms, namely drusen formation, retinal pigment epithelial (RPE) abnormalities in the form of hypopigmentation or hyperpigmentation, atrophic geography of retinal and choriocapillaris pigment epithelium involving the central part of the fovea, and neovascular maculopathy (exudative). Patients are usually older than 50 years old, who manifest with or without vision complaints in the form of central vision loss in one or both eyes [1-5].

ARMD is presently a major cause of blindness in western countries. Worldwide, ARMD sufferers reached 20-25 million people and expected to triple with the increase of elderly population in the next 30-40 years. The World Health Organization estimated that currently 8 million people experiencing blindness were caused by ARMD $[4,5]$

One prevention for ARMD is the provision of antioxidants. Glutathione (GSH) is one of the antioxidants in the body able to transform into reduced GSH. A compound containing sulfhydryl (-SH) group is basically divided into two groups, namely group of protein-SH and non-proteinSH. GSH or y-glutamyl cysteinylglycine is a tripeptide containing cysteine and a source of sulfhydryl, which plays a role in detoxification, transport, metabolic processes, also as a cell antioxidant that works synergistically with fat antioxidants and solves fat peroxidation [6,7]. Previous studies mentioned that GSH was not properly absorbed if administered orally, but some others confirmed that GSH absorption in the intestinal epithelium underwent a specific uptake system. Disorders in GSH circulation process did not rule out the possibility of GSH oral administration [6-10]. Carotenoids, in this case, lutein and zeaxanthin, also possess antioxidant ability by improving macular pigment, which is believed to inhibit retinal damage due to oxidation by inhibiting the entry of blue light, thus reducing the risk of ARMD [11].
This study aimed to determine the efficacy of GSH addition in lutein supplementation to improve the contrast sensitivity of dry type ARMD patients.

\section{METHODS}

This study was a prospective, randomized, controlled trial with parallel group and 1:1 allocation ratio conducted at the Eye Hospital and Moh. Hoesin General Hospital, Palembang, Indonesia, from April 2016 to June 2016. Consents from participants were obtained and legitimated by signing an informed consent. This study obtained ethical approval from the Health Research Ethics Committee adhered to the tenets of the Declaration of Helsinki. No important changes were performed in methods after trial commencement.

\section{Subjects' eligibility}

The study involved 22 dry type ARMD patients with the inclusion criteria of patients with age-related eye disease study (AREDS) category 2, 3, or 4, bilateral, visual acuity with the best correction $>1.0 \operatorname{logMAR}(5 / 50 ; 0.1)$, cooperative, and willing to follow the study until completion. Exclusion criteria were patients with blood glucose levels $>150 \mathrm{mg} / \mathrm{dl}$, signs of infection both in the anterior and posterior segments, optic disc abnormalities, visual axis opacities complicating the assessment of the posterior segment, and consumption of other antioxidants.

\section{Subjects' examination and treatment}

Anamnesis was performed followed by ophthalmology examination to assess the anterior segment utilizing slit lamp (Carl Zeiss, Germany). Ophthalmoscopy examination with a 78 lens or indirect ophthalmoscopy (Neitz Instruments Co., Ltd., Japan) and fundus imaging with VisucamNM/FA (Carl Zeiss, Germany) were performed to establish the ARMD diagnosis. Participants with AREDS category 2, 3, 
and 4 were selected. Patients were randomized by simple randomization using computer-generated tables of random numbers starting from the first row of the first column read from the right. The tables were numbered from 1 to 9 . Patients with the number of $0-4$ were placed in Group A, while patients with the number of 5-9 were placed in Group B. Patients included in Group A were given the treatment of $20 \mathrm{mg}$ lutein (General Nutrition Centers, Inc., Pennsylvania, USA) and $500 \mathrm{mg}$ GSH (General Nutrition Centers, Inc., Pennsylvania, USA), while Group B with $20 \mathrm{mg}$ lutein only. The interventions were sealed in sequential numbered identical containers according to the allocation sequence by an assistant with no clinical involvement in the trial. Treatment was administered orally in capsule preparation and carried out for 30 days.

\section{Contrast sensitivity measurement}

Contrast sensitivity measurement was performed with Lea Numbers ${ }^{\circledR}$ Low Contrast Flip Chart before and after the treatment by a blinded investigator. The utilized lighting was within the illumination range of $60-120 \mathrm{~cd} / \mathrm{m}^{2}$. The lowest visual threshold was determined using $100 \%$ contrast from a distance of $3 \mathrm{~m}$. The threshold used was 3 symbols read correctly from a total of 5 . The reading was repeated until the contrast of $2.5 \%$. If at $2.5 \%$ contrast, symbol reading error at line 1.0 was $<3$, subject was defined as having high contrast sensitivity. If at $2.5 \%$ contrast, symbol reading error at line 1.0 was $>3$, or the reading failed to reach line 1.0, subject was defined as having low contrast sensitivity. Improved contrast sensitivity was defined with a decrease in the contrast value percentage correlated to the distance or increasing distance to the contrast value. There were no changes to trial outcomes after the trial commencement.

\section{Data analysis}

Data were analyzed with paired t-test for the contrast sensitivity measurement and Levene and Fisher tests for the baseline characteristics, processed with SPSS 21.0 (SPSS Inc., Chicago, USA) and presented in narrative and tabulation.

\section{RESULTS}

Recruitment and follow-up were enrolled from April 2016 to June 2016, with 10 study subjects who were obtained for each group, with a total of 20 subjects for both the groups. Treatment group of $20 \mathrm{mg}$ lutein supplementation plus $500 \mathrm{mg}$ GSH possessed slight older mean of age compared to $20 \mathrm{mg}$ lutein group, as shown in Table 1 . However, the difference in the mean of age between the two groups did not differ significantly. In the treatment group of $20 \mathrm{mg}$ lutein supplementation plus $500 \mathrm{mg} \mathrm{GSH}$, there were more men compared to women, whereas in the group of $20 \mathrm{mg}$ lutein, men and women were equal in number. The difference in gender variable of the two groups was not statistically significant.

Table 1: Baseline characteristics

\begin{tabular}{llll}
\hline Characteristics & \multicolumn{2}{l}{ Group } & p value \\
\cline { 2 - 3 } & $\begin{array}{l}\text { Lutein-glutathione } \\
(\boldsymbol{n = 1 0 )}\end{array}$ & $\begin{array}{l}\text { Lutein } \\
(\boldsymbol{n = 1 0 )}\end{array}$ & \\
\hline $\begin{array}{l}\text { Age (year) } \\
\text { Mean } \pm \text { SD }\end{array}$ & $58.33 \pm 5.38$ & $56.50 \pm 5.21$ & $0.571^{\mathrm{a}}$ \\
$\begin{array}{l}\text { Gender } \\
\text { Male } n(\%)\end{array}$ & $6 / 10(60)$ & $5 / 10(50)$ & $0.515^{\mathrm{b}}$ \\
Female $n(\%)$ & $4 / 10(40)$ & $5 / 10(50)$ & \\
\hline
\end{tabular}

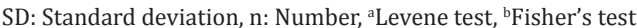

Table 2: Contrast sensitivity improvement on lutein and glutathione treatment

\begin{tabular}{lllll}
\hline \multirow{2}{*}{ Group } & \multicolumn{2}{l}{ Contrast sensitivity (mean \pm SD) } & \multirow{2}{*}{ p value } \\
\cline { 2 - 4 } & Before & After & Improvement & \\
\hline Lutein \pm glutathione & $10.63 \pm 5.65$ & $7.01 \pm 4.21$ & $3.62 \pm 1.44$ & $0.008^{\text {a* }}$ \\
Lutein & $10.25 \pm 6.17$ & $9.00 \pm 6.61$ & $1.25 \pm 0.44$ & $0.177^{\text {a }}$ \\
\hline aPaired t-test, ${ }^{*} \mathrm{p}<0.05$ & & & &
\end{tabular}

Contrast sensitivity before treatment was relatively equal between treatment group of $20 \mathrm{mg}$ lutein plus $500 \mathrm{mg} \mathrm{GSH}$ and $20 \mathrm{mg}$ lutein only, as shown in Table 2. After the treatment, contrast sensitivity improvement was observed in both the groups. Contrast sensitivity improvement of the group with additional GSH was 3-fold of the lutein group only, and the before-after difference was statistically significant, whereas in the treatment group of $20 \mathrm{mg}$ lutein, no significant difference of contrast sensitivity was observed after treatment.

\section{DISCUSSION}

In this study, treatment group with additional GSH and lutein only possessed no statistically different mean of age. The mean of age in lutein and GSH group was $58.33 \pm 5.38$ years and the lutein group was $56.50 \pm 5.21$ years. This was in accordance with previous study which stated that ARMD sufferers were mostly older than 50 years old, with or without vision complaints [1-5]. This may be due to the contrast sensitivity that decreases according to age and becomes sensitive to the effects of normal aging or a disease. The sensitivity of mesopic contrast decreases at the age of 50 years and over, followed by a decrease in photopic contrast sensitivity 10 years later. This corresponds to agerelated decrease in the number of rods in parafovea, which is more severe in cases of ARMD [12].

The result in this study which exhibited no significant difference in gender variable of ARMD patients was supported by Tang and Zhou study that conducted a contrast sensitivity examination with two stimuli. It was stated that there was no significant difference observed between men and women [13]. Similar results were also found in a study by Solberg and Brown who discovered that men and women exhibited no difference in contrast sensitivity and reaction time at spatial frequency tests [14]. One study that showed the difference in gender variable in ARMD patients was conducted by Richer et al., where older women experienced higher incidence of ARMD [15]. This difference was due to the small number of samples compared to previous studies.

Treatment group with only $20 \mathrm{mg}$ lutein yielded no significant contrast sensitivity improvement in this study. This was in contrast to previous studies, including those conducted by Landrum et al., Olmedila et al., and Dagnelie et al. who evaluated visual function including contrast sensitivity, after lutein administration with doses varying between 10 and $40 \mathrm{mg}$, with observed improvements [16-18]. In 1997, Landrum et al. stated that macular pigment density increased evenly within 20-40 days with $30 \mathrm{mg}$ lutein supplementation per day [16]. Gale et al. stated that the high amount of macular pigment would maintain visual sensitivity [19]. Olmedilla et al. discovered that improvement of visual function (visual acuity and glare sensitivity) occurred within 3 months after 12-15 mg of lutein supplementation given 3 times a week in patients with ARMD [17], while Dagnelie et al. suggested that improvements in visual acuity and visual field began 2-4 weeks after the initiation of $40 \mathrm{mg}$ lutein supplementation in patients with retinitis pigmentosa and other retinal degeneration [18]. Landrum et al. who observed that macular pigment density within 20-40 days from the initiation of $30 \mathrm{mg}$ lutein supplementation in normal subjects showed an even increase, which was preceded by an increase in serum lutein concentration 10 day after the initiation of lutein supplementation [16]. Antioxidant properties of lutein were observed in a study by Purushothaman et al. as carbofuran-induced oxidative stress in rats was attenuated by lutein administration. Lutein reduced the neurotoxicity and tissue toxicity as observed from the elevated serum and tissue levels of acetylcholinesterase and decreased levels of creatine kinase, lactate dehydrogenase, and $\gamma$-glutamyltransferase [20].

Although contrast sensitivity improvement was observed in the $20 \mathrm{mg}$ lutein group, it was not statistically significant. Possible causes to be considered were imperfect absorption of lutein due to inadequate carrier material, decreased intestinal villous absorptive function, and degenerative damage in RPE, resulting in insufficient macular pigment density to improve contrast sensitivity within 30 days after lutein administration. To prove this, further study is suggested with a 
longer observational period or the determination of sample size, where previous studies conducted the span of observation for 12 months. Lutein molecule possesses poor water solubility and solution stability, susceptible to be degraded by oxygen and physical properties as light and heat. Innovative system of delivery is needed for lutein to be applied in clinical settings to preserve stability and elevate the level of uptake [21].

This study implicated that GSH was a favorable treatment option in ARMD. GSH addition in lutein supplementation provoked a significant better contrast sensitivity improvement compared to lutein only in dry ARMD patients. To be underlined, GSH is not well absorbed in the digestive tract, but a combination with several other antioxidants and standards or with $\mathrm{N}$-acetylcysteine, alpha-lipoic acid, flavonoid silymarin, and L-glutamine has been proven to support and increase GSH levels in serum and tissues. This is also supported by Richer et al. which showed that the use of lutein in combination with carotenoids and other antioxidants or minerals significantly improved macular pigment density, visual acuity, and almost all visual quality examinations including contrast sensitivity [15]. When RPE cells cultured from humans were treated with $200 \mu \mathrm{m}$ dimethyl fumarate (DMF) for $24 \mathrm{~h}$, GSH concentration increased by 2.5 times. Increased level of GSH might be accompanied by a moderate increase in activity of GSH S-transferase, both of which lead to increased protection against peroxide poisoning. Without DMF treatment, almost all cells were lead to death with the treatment of 300-500 $\mu \mathrm{m}$ tertbutyl hydroperoxide (t-BHP) for $24 \mathrm{~h}$. Pre-incubation of cells with DMF for $24 \mathrm{~h}$ provided protection against t-BHP induced by GSH oxidation, and the cells became more resistant to oxidative damage of t-BHP $[22,23]$.

The improvement of contrast sensitivity in this study was due to the mutually reinforcing effects of lutein and GSH. GSH combination with other antioxidants increased the amount of GSH in the serum and tissues, thereby increasing the number of macular pigments density, RPE cells, and other cells in the body. This was consistent with a study conducted by Sabour-Pickett et al. which discovered that there was an increase in macular pigment density after lutein supplementation of $10 \mathrm{mg}$ or a combination with other antioxidants or vitamins for 12 months [24]. GSH itself is a normal antioxidant present in the body, but exogenous addition will elevate its level in the body and tissues.

This study had limitations of small sample size and relatively short observation period. A larger sample size and a longer follow-up were required for better observation results. It is necessary to perform examination using a standard tool for contrast sensitivity assessments such as the Pelli Robson chart in future studies.

\section{CONCLUSION}

GSH addition in lutein supplementation was favorable as treatment option in ARMD as they exhibited better contrast sensitivity improvement in dry ARMD patients.

\section{ACKNOWLEDGMENT}

The authors delivered warm gratitude for the Department of Ophthalmology, Dr. Moh. Hoesin General Hospital, Palembang, Indonesia, for their support.

\section{AUTHORS' CONTRIBUTIONS}

All authors conceived in concepts, design, data processing, manuscript preparation, and revision.

\section{CONFLICTS OF INTEREST}

There were no potential conflicts of interest.

\section{REFERENCES}

1. Schubert HD. Retina and vitreous. In: Cantor LB, Rapuano CJ, Cioffi GA, editors. Basic and Clinical Science Course 2014-2015. Sec. 12. San Francisco: American Academy of Ophthalmology; 2014. p. 55-63.

2. Klein R, Peto T, Bird A, Vannewkirk MR. The epidemiology of agerelated macular degeneration. Am J Ophthalmol 2004;137:486-95.

3. Schubert HD. Retina and vitreous. In: Cantor LB, Rapuano CJ, Cioffi GA, editors. Basic and Clinical Science Course 2014-2015. Sec. 12. San Francisco: American Academy of Ophthalmology; 2014. p. 281-7.

4. Amin HI, McDonald HR, Johnson RN, Ai E, Schatz H. Acquired macular disease. In: Tasman W, Jaeger EA, editors. Duane's Clinical Ophthalmology [CD-ROM]. Baltimore: Lippincott Williams and Wilkins; 2003

5. Chopdar A, Chakravarthy U, Verma D. Age related macular degeneration. BMJ 2003;326:485-8.

6. Townsend DM, Tew KD, Tapiero H. The importance of glutathione in human disease. Biomed Pharmacother 2003;57:145-55.

7. Pereira RB, Sousa C, Costa A, Andrade PB, Valentão P. Glutathione and the antioxidant potential of binary mixtures with flavonoids: Synergism and antagonisms. Molecules 2013;18:8858-72.

8. Meschino J. Glutathione: The body's master detoxifier and antioxidant. Dyn Chiropr 2009;27:1-11.

9. Lapenna D, de Gioia S, Ciofani G, Mezzetti A, Ucchino S, Calafiore AM. Glutathione-related antioxidant defenses in human atherosclerotic plaques. Circulation 1998;97:1930-4.

10. Berendschot TT, Goldbohm RA, Klöpping WA, van de Kraats J, van Norel J, van Norren D. Influence of lutein supplementation on macular pigment, assessed with two objective techniques. Invest Ophthalmol Vis Sci 2000;41:3324-6.

11. Seddon JM, Ajani UA, Sperduto RD, Hiller R, Blair N, Burton TC, et al. Dietary carotenoids, Vitamin A, C, and E, and advanced agerelated macular degeneration. Eye Disease Case Control Study Group. JAMA 1994;272:1413-20

12. Hamid AA, Aiyelaagbe OO, Usman LA, Ameen OM, Lawal A. Antioxidant: Its medicinal and pharmacological applications. Afr J Pure Appl Chem 2010;4:142-51.

13. Tang Y, Zhou Y. Age-related decline of contrast sensitivity for secondorder stimuli: Earlier onset, but slower progression, than for first-order stimuli. J Vis 2009;9:18.

14. Solberg JL, Brown JM. No sex differences in contrast sensitivity and reaction time to spatial frequency. Percept Mot Skills 2002;94:1053-5.

15. Richer S, Stiles W, Statkute L, Pulido J, Frankowski J, Rudy D, et al. Double-masked, placebo-controlled, randomized trial of lutein and antioxidant supplementation in the intervention of atrophic age-related macular degeneration: The veterans LAST study (lutein antioxidant supplementation trial). Optometry 2004;75:216-30.

16. Landrum JT, Bone RA, Joa H, Kilburn MD, Moore LL, Sprague KE. A one year study of the macular pigment: The effect of 140 days of a lutein supplement. Exp Eye Res 1997;65:57-62.

17. Olmedilla B, Granado F, Blanco I, Vaquero M, Cajigal C. Lutein in patient with age-cataract and age related macular degeneration: Along term supplementation study. J Sci Food Agric 2001;81:904-99.

18. Dagnelie G, Zorge IS, McDonald TM. Lutein Improves visual function in some patient with retinal degeneration: A pilot study via internet. Optometry 2000;71:147-64.

19. Gale CR, Hall NF, Phillips DI, Martyn CN. Lutein and zeaxanthin status and risk of age-related macular degeneration. Invest Ophthalmol Vis Sci 2003;44:2461-5.

20. Purushothaman BP, Valsan G, Kuttan R. Oxycarotenoid lutein reverses the toxicity induced by carbofuran in wistar rats. Int J Pharm Pharm Sci 2018;10:10-5

21. Chaiyasan W, Sangly P. Development and characterization of topical ophthalmic formulations containing lutein-loaded mucoadhesive nanoparticles. Int J Pharm Pharm Sci 2016;8:261-6.

22. Aw TY, Wierzbicka G, Jones DP. Oral glutathione increases tissue glutathione in vivo. Chem Biol Interact 1991;80:89-97.

23. Allen ND, Jason and Ryan D. Bradley. Effects of oral glutathione supplementation on systemic oxidative stress biomarkers in human volunteers. J Altern Complement Med 2011;17:827-33.

24. Sabour-Pickett S, Beatty S, Connolly E, Loughman J, Stack J, Howard A, et al. Supplementation with three different macular carotenoid formulations in patients with early age-related macular degeneration. Retina 2014;34:1757-66. 